\title{
INTERCULTURALIDADE E EDUCAÇÃO NA AMÉRICA LATINA: uma construção plural, original e complexa
}

\author{
Interculturallity and education in Latin \\ America: a plural, original and \\ complex construction
}

\author{
Vera Maria Ferrão Candau ${ }^{[a]}$, Kelly Russo ${ }^{[b]}$ \\ [a] Professora titular do Departamento de Educação, Pontifícia Universidade Católica do \\ Rio de Janeiro (PUC-Rio), Rio de Janeiro, RJ - Brasil, e-mail: vmfc@puc-rio.br \\ ${ }^{[b]}$ Doutoranda do Departamento de Educação, Pontifícia Universidade Católica do Rio \\ de Janeiro (PUC-Rio), Rio de Janeiro, RJ - Brasil, e-mail: kellyrussobr@yahoo.com.br
}

\section{Resumo}

Este trabalho se situa no contexto da pesquisa "Multiculturalismo, Direitos Humanos e Educação", desenvolvida no período de 2006 a 2009, com o apoio do CNPq. Analisa a construção da perspectiva da educação intercultural no continente latino-americano, destacando as principais contribuições que têm enriquecido esta abordagem, tanto do ponto de vista teórico quanto de suas implicações nos processos

Rev. Diálogo Educ., Curitiba, v. 10, n. 29, p. 151-169, jan./abr. 2010 
educacionais e sociopolíticos dos diferentes países. Parte das contribuições da educação escolar indígena, considerada a origem desta preocupação em nosso continente, apresenta contribuições dos movimentos negro, tendo presente sua diversidade de configurações no continente, e destaca as experiências de educação popular desenvolvidas no continente e, neste contexto, a figura de Paulo Freire como especialmente relevante para o aprofundamento da perspectiva da educação intercultural. Assinala também a incorporação da educação intercultural nas reformas curriculares dos anos 90 e a tendência a transformá-la em elemento funcional aos sistemas sociopolíticos vigentes. Aborda a perspectiva crítica da interculturalidade, que a considera como um dinamismo orientado a uma transformação estrutural das sociedades latino-americanas. Nesta ótica, dá especial ênfase às reflexões do grupo "modernidadecolonialidade", constituído por um conjunto de especialistas que centram sua análise nas relações de poder presentes no continente em todo seu processo de formação histórica. Este estudo procura evidenciar o aspecto plural, complexo e original da construção da perspectiva da educação intercultural na América Latina.

Palavras-chave: Educação intercultural. América Latina. Interculturalidade crítica. Modernidadecolonialidade.

\begin{abstract}
This article is part of the research entitled "Multiculturalism, Human Rights and Education", developed between 2006 and 2009, with the support of CNPq. It intends to analyze the construction of an intercultural education perspective in Latin America, accentuating the importance of the main contributions which have enriched and improved this approach, both from the theoretic point of view and the implications in the educational and sociopolitical processes in different countries. The starting point is the indigenous school education contribution, considered by the unanimity of the experts as the place where the intercultural preoccupations started. It describes and
\end{abstract}

Rev. Diálogo Educ., Curitiba, v. 10, n. 29, p. 151-169, jan./abr. 2010 
characterizes the main phases of the indigenous school education development. It also shows the Negro Movements contributions, taking into account the variety of their reality in the continent. The richness of the popular education experiences developed in the continent is also emphasized and, in this context, the contribution of Paulo Freire as an especially important thinker for the improvement of the intercultural education perspective. It also marks the intercultural education incorporation in the curriculum reforms of the 1990s and the tendencies in turning it into a functional element for the current sociopolitical systems. It discusses the interculturallity critical perspective, which considers it as a dynamism directed to a structural transformation of the Latin American societies. From this view, it gives special attention to the reflections of the group "modernity-coloniality", composed by some specialists of various countries that focus their analyses at power relations which are part of the continent historical conformation process. Through all the text, we try to show the plural, complex and original aspect of the construction of an intercultural education perspective in Latin America.

Keywords: Intercultural education. Latin America. Interculturallity critical perspective. Modernity-coloniality.

\section{INTRODUÇÃO}

Diferentes grupos socioculturais invadem os cenários públicos, tanto no âmbito internacional como em diversos países do continente. Tensões, conflitos, tentativas de diálogo e negociação se multiplicam. Em cada contexto, essa problemática adquire uma configuração específica, articulada com as diversas construções históricas e políticoculturais de cada realidade.

A afirmação das diferenças - étnicas, de gênero, orientação sexual, religiosas, entre outras - se manifesta em todas as suas cores, sons, ritos, saberes, crenças e diversas linguagens. As problemáticas são múltiplas, visibilizadas pelos movimentos sociais, que denunciam

Rev. Diálogo Educ., Curitiba, v. 10, n. 29, p. 151-169, jan./abr. 2010 
injustiças, desigualdades e discriminações, reivindicando igualdade de acesso a bens e serviços e reconhecimento político e cultural. Esses movimentos nos colocam diante da realidade histórica do continente, marcada pela negação dos "outros", física ou simbólica, ainda presente nas sociedades latino-americanas.

A construção dos estados nacionais no continente latinoamericano supôs um processo de homogeneização cultural em que a educação escolar exerceu um papel fundamental, tendo por função difundir e consolidar uma cultura comum de base ocidental e eurocêntrica, silenciando e/ou inviabilizando vozes, saberes, cores, crenças e sensibilidades.

É neste universo particular de questões, conflitos e buscas que situamos a emergência da perspectiva intercultural no continente. Um processo onde redistribuição e justiça cultural são polos que se exigem mutuamente e que compõem bandeiras de luta na atual dinâmica social e política da América Latina.

Neste trabalho, partimos da afirmação de que a preocupação por uma educação que respeite e valorize as diferenças culturais não é exclusiva da América Latina, mas emerge e se configura de modo original no nosso contexto. Desde 2006 vimos desenvolvendo um projeto de pesquisa, com o apoio do CNPq, intitulado Multiculturalismo, Direitos Humanos e Educação: a tensão entre igualdade e diferença, que tem como um de seus objetivos analisar como a problemática da educação intercultural tem se desenvolvido em diferentes países latinoamericanos.

Perseguindo este objetivo, foram realizados diferentes seminários e entrevistas a professores universitários e militantes de movimentos sociais e organizações não governamentais do Peru, Bolívia, Equador, Guatemala e México. Por meio das entrevistas e do levantamento bibliográfico regional, procuramos identificar as diferentes perspectivas e questões suscitadas pela educação intercultural em cada um desses países e no continente como um todo.

Existe atualmente ampla produção latino-americana sobre essa temática, de modo especial nos países de colonização espanhola e, entre estes, nos países andinos. A produção brasileira vem crescendo de modo significativo nos últimos anos, principalmente após a Constituição de 1988, que reconhece a especificidade cultural de populações indígenas e quilombolas existentes no país. No entanto,

Rev. Diálogo Educ., Curitiba, v. 10, n. 29, p. 151-169, jan./abr. 2010 
ainda precisa ser aprofundado o diálogo entre a produção brasileira e a dos diferentes países da América de colonização espanhola sobre as questões suscitadas na atualidade pela educação intercultural.

É a partir dessas observações preliminares que situamos o presente trabalho que pretende unicamente, com caráter provisório e inicial, oferecer algumas aproximações à problemática das relações entre interculturalidade e educação no continente, a partir do levantamento bibliográfico e das entrevistas realizadas.

\section{Um ponto de partida consensual: a educação indígena}

Toda a produção bibliográfica que analisamos, assim como os depoimentos dos(as) entrevistados(as) dos diferentes países foram unânimes em afirmar que o termo interculturalidade surge na América Latina no contexto educacional e, mais precisamente, com referência à educação escolar indígena. Nesse sentido, é importante que apresentemos brevemente a trajetória da educação escolar indígena no continente.

Neste resgate não pretendemos negar a grande diversidade de situações e os diferentes contextos onde se dá o seu desenvolvimento. Também não propomos a existência de uma linha única e progressiva da história da educação escolar indígena na América Latina, visto que o início de uma nova fase não significa o término da anterior, pois em muitos momentos elas ocorrem sobrepostas umas às outras. Apresentamos aqui apenas um esforço de identificar as raízes do pensamento intercultural no continente.

Com essas ressalvas feitas, podemos identificar quatro principais etapas no desenvolvimento da educação escolar indígena. A primeira se desenvolve do período colonial até as primeiras décadas do século XX e pode ser caracterizada por uma violência etnocêntrica explícita de imposição da cultura hegemônica sobre as populações indígenas. Eliminar o "outro" foi a tônica do período colonial e a partir das primeiras décadas do século XX essa eliminação se configura de outra forma: a "assimilação". Base de construção da homogeneidade requerida pelos estados nacionais modernos.

Nessa segunda etapa, surgiram as primeiras escolas estatais bilíngues voltadas para os povos indígenas. Pela primeira vez, outras línguas além da oficial conviveriam no espaço escolar. Mas com raras

Rev. Diálogo Educ., Curitiba, v. 10, n. 29, p. 151-169, jan./abr. 2010 
e preciosas exceções ${ }^{1}$, essas escolas viam o bilinguismo apenas como uma etapa de transição necessária: um modo para alfabetizar e "civilizar" mais facilmente, povos inteiros. Uma das agências de maior influência para o estabelecimento do bilinguismo de transição na América Latina foi a organização estadunidense Summer Institute of Linguistics. Foi graças às suas atividades com diferentes governos latino-americanos, que se estabeleceu uma percepção comum sobre as "diferentes etapas" necessárias para a "transição" do índio à categoria de "trabalhador rural" ou "campesino". Nessa proposta, a escola era vista como um "motor de desenvolvimento comunitário" onde, "através de explicações dadas na língua materna, a criança conseguiria entender muito melhor e transmitir para os pais os conceitos e valores da cultura nacional" (KINDALL; JONES, 1958 apud COLLET, 2001, p. 77).

Com esse objetivo fundamental, línguas indígenas foram sistematizadas e transcritas para a escrita e essa concepção de bilinguismo irá influenciar fortemente as políticas educativas voltadas às comunidades indígenas em toda a América Latina até a década de 1970, quando se inicia uma nova etapa de desenvolvimento da educação escolar indígena a partir das experiências alternativas protagonizadas por lideranças comunitárias, em parceria com universidades e setores progressistas da Igreja Católica. Entre as décadas de 1960 e 1980, organizações governamentais e não-governamentais voltadas para a defesa da causa indígena começaram a emergir no cenário internacional.

Neste novo período foram produzidos materiais didáticos alternativos e programas de educação bilíngue que, apesar de ainda buscarem uma melhor "integração" dos grupos às sociedades nacionais, reconheciam o direito desses povos de fortalecer e manter a cultura local. O bilinguismo deixa de ser visto apenas como instrumento

\footnotetext{
Neste mesmo período, alguns educadores de diferentes países da América Latina mostraramse insatisfeitos com essa visão limitada do bilinguismo e procuraram desenvolver formas alternativas para a alfabetização de alunos indígenas. López e Küper (1999) exemplificam algumas delas, citando as experiências ocorridas na cidade de Cayambe, no Equador ou em Puno, no Peru. Destacamos também, e de modo especial, a experiência de Warisata Escola-Ayllu, desenvolvida na Bolívia entre 1931 e 1940, organizada e estruturada a partir do sistema de referências culturais e sociais existentes na sociedade Aimara. Além da prática bilíngue, Warisata incluiu uma dinâmica cotidiana que respondia e respeitava a relação comunitária, significando, talvez, um primeiro exemplo de educação intercultural bilíngue que conhecemos hoje. Para saber mais sobre esta experiência, ver: Pérez (1962) e Mejía Vera (2006).
}

Rev. Diálogo Educ., Curitiba, v. 10, n. 29, p. 151-169, jan./abr. 2010 
civilizatório para ser considerado de importância fundamental para a continuidade dos próprios grupos minoritários.

No Peru, a Universidade Nacional Maior de São Marcos, por exemplo, exerceu grande influência no desenvolvimento de um projetopiloto de educação bilíngue com maior participação de lideranças quéchuas durante a década de 1970 (LÓPEZ; KÜPER, 1999), e no Brasil, nesse mesmo período, a Universidade Estadual de Campinas desenvolveu o Projeto de Educação Indígena "Uma experiência de Autoria", que defendia como proposta básica a integração entre o processo cultural local e o saber sistematizado universal, procurando, assim, valorizar as práticas sociais dos povos indígenas integrantes do programa (FERREIRA, 2001, p. 91). Apesar de importantes, essas experiências e outras semelhantes permaneceram isoladas, sem o apoio das instituições governamentais até o final da década de 1980, quando se inicia o que denominamos de quarta etapa na educação escolar indígena do continente, quando os próprios indígenas passam a participar das definições para o setor educativo.

$\mathrm{Na}$ nova configuração, o bilinguismo deixa de ser visto apenas como estratégia de transição ou meio para manutenção de uma cultura ameaçada, para ser inserido em um discurso mais amplo, onde a perspectiva intercultural pressiona o modelo escolar clássico e inclui nela não apenas diferentes línguas, mas, sobretudo, diferentes culturas. Lutas indígenas antes isoladas, protagonizadas por cada etnia em particular, passaram a ser unidas sob uma identidade comum "indígena" e a ter reconhecimento e espaço internacional principalmente nas últimas décadas. ${ }^{2}$ López (2004) lembra que, tanto em países com população majoritariamente indígena, como é o caso da Bolívia (aproximadamente $65 \%$ ), como naqueles com população minoritária, como é o caso do Brasil $(0,3 \%)$, tem surgido, cada vez mais forte, uma exigência comum por escolas coordenadas e gerenciadas por professores indígenas.

A experiência de escolas interculturais indígenas desenvolvidas no continente incluíram uma nova dimensão sobre a ideia mesma de cultura no espaço escolar. Diferentes línguas foram o passo inicial para

São muitos os exemplos de encontros internacionais realizados e organizados por lideranças indígenas de diferentes regiões do continente. Estes encontros também significam um interessante espaço de aprendizagem mútua entre os integrantes, que vivenciam realidades muito diferentes em cada contexto nacional. Sobre o tema ver: Mato, 2003; Russo, 2007.

Rev. Diálogo Educ., Curitiba, v. 10, n. 29, p. 151-169, jan./abr. 2010 
a proposição de um diálogo entre diferentes culturas. Outros grupos contribuíram para a ampliação da discussão sobre educação e interculturalismo, entre eles estão os movimentos negro latino-americanos.

\section{Interculturalidade e movimentos negros}

A construção de uma identidade nacional para cada novo Estado latino-americano significou a exclusão e invisibilidade para todos aqueles que não se reconheciam na cultura europeia. Assim como os indígenas, culturas de matriz africana não encontraram espaço na educação escolar e até hoje encontram dificuldade de difusão no continente.

Importante destacar que a situação dos grupos negros no continente varia muito em relação à realidade de cada país. Se em alguns casos foi praticamente eliminada, como na Argentina, em outros constitui a grande maioria da população, como em Cuba ou Haiti. Há situações em que estão circunscritos a algumas regiões e/ou núcleos rurais, como no Equador ou Bolívia, em outras estão presentes nas principais zonas urbanas do respectivo país, como é o caso do Brasil ou Colômbia. Sua presença permeia de variadas formas as sociedades nacionais em diferentes âmbitos, e diversas proporções.

Apesar da realidade dos grupos e movimentos negros ser muito heterogênea e diferenciada na região, é possível afirmar que esses grupos foram, em geral, reduzidos a uma posição de não cidadania até a metade do século passado. Torna-se necessário lembrar que o regime escravocrata persistiu em alguns países até o final do século XIX.

A situação dos afro-descentes na maior parte do continente tem sido configurada por processos de violência e exclusão física, social e simbólica. No entanto, em diferentes nações, foram muitas as lutas de grupos afro-descendentes por condições de vida dignas e combate à discriminação e ao racismo. Esses grupos têm se caracterizado pela resistência e por suas lutas contra o racismo em suas diferentes manifestações, assim como pela afirmação de direitos e plenitude de cidadania, o que supõe reconhecimento de suas identidades culturais.

Mas, apesar desses temas serem bastante atuais nas discussões sobre educação e interculturalismo no continente, foi difícil encontrar na produção bibliográfica latino-americana sobre a educação intercultural, referências às contribuições dos grupos e movimentos

Rev. Diálogo Educ., Curitiba, v. 10, n. 29, p. 151-169, jan./abr. 2010 
negros. Em geral, são fartas as informações sobre o desenvolvimento da educação escolar indígena e escassas aquelas que tenham como foco a ação de outros grupos populares.

Por essa razão, consideramos importante destacar no contexto desse estudo - que visa rever a trajetória de desenvolvimento da educação intercultural em nosso continente - algumas contribuições dos movimentos negros que têm tido uma atuação significativa na esfera pública de seus respectivos países. Um primeiro aspecto referese à denúncia das diferentes manifestações da discriminação racial presentes nas sociedades latino-americanas. Nessas realidades, em geral predomina uma ideologia que privilegia os euro-descendentes e a branquidade, inferiorizando e subalternizando os grupos que não podem ser incorporados nesta categoria e suas contribuições para a construção das respectivas sociedades.

Igualmente importante é o reconhecimento de que no continente se desenvolveu, com diferentes denominações, uma apologia da mestiçagem, como a expressão democracia racialno nosso país, que configurou um imaginário sobre as relações sociais e raciais mantidas entre os diferentes grupos presentes nas sociedades latino-americanas caracterizado pela cordialidade. Elimina-se, assim, o conflito, continuando a perpetuar estereótipos e preconceitos, pois, se seguirmos a lógica de que os diferentes grupos étnico-raciais desde o início do processo colonizador foram se integrando "cordialmente", podemos pensar que as diferentes posições hierárquicas entre eles deve-se à capacidade e empenho dos indivíduos e/ ou à inferioridade de determinados grupos. Essa ideia se disseminou no imaginário social contribuindo para que as sociedades não se reconhecessem como hierarquizadoras, discriminadoras e racistas.

O desafio que se coloca, neste sentido, é desvelar, desconstruir os estereótipos raciais e a visão do "racismo cordial" presente nas sociedades latino-americanas, apesar desta expessão ser em si mesma contraditória. Ao mesmo tempo, requer o reconhecimento da diferença como um dos elementos fundamentais de uma sociedade democrática.

Os movimentos negros organizados têm também promovido leituras alternativas do processo histórico vivido e do papel dos negros na formação dos vários países latino-americanos. Demandas por reparações por parte dos estados e das sociedades, por medidas que visem ressarcir os afro-descendentes dos danos sofridos sob o regime escravista, assim como pelas políticas explícitas ou tácitas de

Rev. Diálogo Educ., Curitiba, v. 10, n. 29, p. 151-169, jan./abr. 2010 
embranquecimento da população são apresentadas e se referem a diferentes âmbitos sociais, políticos e culturais.

No que diz respeito à educação, incluem políticas orientadas ao ingresso, permanência e sucesso na educação escolar, valorização das identidades culturais negras, incorporação nos currículos escolares e nos materiais pedagógicos de componentes próprios das culturas negras, assim como dos processos históricos de resistência vividos pelos grupos negros e suas contribuições à construção histórica dos diferentes países. A valorização da ancestralidade africana constitui um dos elementos fundamentais desta abordagem, principalmente para aqueles grupos que lutam pelo reconhecimento de territórios e neles procuram implementar outros modelos de desenvolvimento.

Outro elemento importante que vem sendo incorporado por vários países são as políticas de ação afirmativa dirigidas aos afrodescendentes em diferentes âmbitos da sociedade, do mercado de trabalho ao ensino superior. Esta é uma questão que vem provocando muitas discussões e polêmicas, mas que tem avançado de modo significativo em diferentes países. No Equador, um dos documentos produzidos pelo Centro Cultural Afro-Equatoriano propôs, em 2001, o uso do termo "etnoeducação" para definir processos educativos que "despertem o sentimento de pertencimento do negro" e que possibilite a construção de um modelo educativo que permita "um reencontro com o que somos" ao considerar os aportes das diferentes etnias que compuseram a diversidade cultural latino-americana (WALSH; GARCÍA, 2002).

Propostas como essas questionam o discurso e as práticas eurocêntricas, homogeinizadoras e monoculturais dos processos sociais e educativos e colocam no cenário público questões referidas à construção de relações étnico-raciais nos contextos latino-americanos. Desvelam o racismo e as práticas discriminatórias que perpassam o cotidiano das nossas sociedades e instituições educativas e promovem o reconhecimento e valorização das diferenças culturais, componentes fundamentais para a promoção de uma educação intercultural.

\section{A educação popular e a perspectiva intercultural}

Outra contribuição importante para o caráter particular do desenvolvimento da educação intercultural no continente, diz respeito

Rev. Diálogo Educ., Curitiba, v. 10, n. 29, p. 151-169, jan./abr. 2010 
às experiências de educação popular realizadas ao longo de toda a América Latina, particularmente a partir dos anos 60. Como as anteriores, essa contribuição também se dá em um universo heterogêneo, com desdobramentos diferenciados nos diversos contextos.

Privilegiaram os âmbitos de educação não formal tendo, no entanto, principalmente a partir do final da década de 1980 e inícios dos anos 90, exercido impacto nas propostas de renovação de diversos sistemas escolares. Sua principal contribuição na perspectiva deste trabalho foi a de a firmar a intrínseca articulação entre processos educativos e os contextos socioculturais em que estes se situam, colocando assim os universos culturais dos atores implicados no centro das ações pedagógicas.

Certamente a inspiração de Paulo Freire constitui a marca característica deste movimento. No início da década de 1960, a sua proposta de alfabetização e educação de adultos, experimentada no nordeste brasileiro, adquiriu grande visibilidade no âmbito nacional. Sabemos que sua posição não pode ser reduzida a um "método" pedagógico. Supõe uma postura filosófica e política, uma leitura do mundo, da sociedade em que vivemos, das formas de intervir nos processos sociopolíticos.

$\mathrm{Na}$ perspectiva freiriana,

a cultura não é só a manifestação artística e intelectual que se expressa no pensamento. A cultura manifesta-se, sobretudo, nos gestos mais simples da vida cotidiana. Cultura é comer de modo diferente, é dar a mão de modo diferente, é relacionar-se com o outro de outro modo. A meu ver, a utilização destes três conceitos cultura, diferenças, tolerância - é um modo novo de usar velhos conceitos. Cultura para nós, gosto de frisar, são todas as manifestações humanas, inclusive o cotidiano e é no cotidiano que se dá algo essencial: o descobrimento da diferença (FAUNDEZ; FREIRE, 1985, p. 34).

O reconhecimento da legitimidade do background cultural do analfabeto não era, para Paulo Freire, uma mera estratégia metodológica. Trazia no seu bojo um modo de lidar com a diferença cultural. Mais do que um respeito distante e asséptico por essa diferença, enfatiza-se e estimula-se a troca entre os sujeitos e os saberes presentes nas relações pedagógicas. Objetivava também o empowerment desse adulto, sempre

Rev. Diálogo Educ., Curitiba, v. 10, n. 29, p. 151-169, jan./abr. 2010 
em um sentido explicitamente referido às classes sociais subalternizadas e excluídas.

Os "Círculos de Cultura" se multiplicaram por todo o território nacional até sua eliminação, como consequência do golpe militar de 1964. No entanto, o legado de Paulo Freire já havia penetrado profundamente nas mentalidades e nas práticas principalmente dos educadores populares. O exílio fez com que se multiplicassem as experiências promovidas por Paulo Freire. Seu olhar se amplia. Sua produção bibliográfica se diversifica em diálogo com variadas realidades. Em diferentes países da América Latina, África, Ásia e Europa sua influência se faz presente. As contribuições do seu pensamento são hoje valorizadas mundialmente e constituem uma das referências iniludíveis das buscas de construção de propostas educativas que tenham presente os diferentes contextos socioculturais e o diálogo entre diversos saberes.

Pelo reconhecimento da relevância da dimensão cultural nas relações pedagógicas e pelo método dialógico que propõe implementar nos processos educativos, pode-se considerar que o pensamento de Paulo Freire já adiantava aspectos importantes do que hoje se configura como a perspectiva intercultural na educação. Segundo Gohn (2002, p. 67),

nos anos 90 Freire destaca ainda mais a dimensão cultural nos processos de transformação social e o papel da cultura no ato educacional. Além de reforçar seus argumentos em defesa de uma educação libertadora que respeite a cultura e a experiência anterior dos educandos, Freire alerta para as múltiplas dimensões da cultura, principalmente a cultura midiática. Ele chama atenção para o fato de que ela poderá despertar-nos para alguns temas geradores que o próprio saber escolar ignora, ou valoriza pouco, como a pobreza, a violência, etc. Destaca também que a mídia trabalha e explora a sensibilidade das pessoas e por isso consegue atrair e monopolizar as atenções. Seus livros escritos nos anos 90 - de estilo mais literário - revelam um pensador preocupado com o futuro da sociedade em que vivemos, dado o crescimento da violência, da intolerância e das desigualdades sócio-econômicas. Ele destacará a importância da ética e de uma cultura da diversidade. O

Rev. Diálogo Educ., Curitiba, v. 10, n. 29, p. 151-169, jan./abr. 2010 
tema da identidade cultural ganha relevância na obra de Freire, assim como o da interculturalidade.

\section{Reformas educativas e interculturalidade}

Ao longo de 1980 e 1990, onze países latino-americanos reconheceram em suas Constituições o caráter multiétnico, pluricultural e multilíngue de suas sociedades ${ }^{3}$. Como consequência, políticas públicas na área educativa precisaram contemplar as diferenças culturais.

Nesse sentido, as diferentes reformas na área de educação incorporam a perspectiva intercultural, seja como um dos eixos articuladores dos currículos escolares, seja introduzindo questões relativas às diferenças culturais como temas transversais. No entanto, se este alargamento do conceito e de seu impacto sobre as políticas públicas pode ser visto como um significativo progresso, não deixa de estar permeado por fortes ambiguidades, pois esta incorporação se dá no contexto de governos que estão comprometidos com a implementação de políticas de caráter neoliberal, que assumem a lógica da globalização hegemônica e a agenda dos principais organismos internacionais.

A incorporação do discurso da interculturalidade neste contexto se dá com uma abordagem orientada a inibir conflitos explícitos ou latentes, e não provocar mudanças de caráter estrutural. São incorporados alguns aspectos da diversidade cultural, orientados a promover a tolerância, o respeito mútuo e maiores espaços de expressão dos diferentes grupos socioculturais, mas sempre limitada. Conforme denominado pelo pesquisador peruano Fidel Tubino (2005) uma "interculturalismo funcional".

A partir das entrevistas realizadas com especialistas latinoamericanos de diferentes países, é possível afirmar que segundo esta lógica, a educação intercultural é orientada, em seus respectivos países, para determinados grupos étnicos, em geral indígenas, e não é incorporada de modo consistente nos processos educativos oferecidos a toda a população.

\footnotetext{
3 Argentina, Bolívia, Brasil, Colômbia, Equador, Guatemala, México, Nicarágua, Paraguai, Peru e Venezuela. Outros quatro países aderiram de modo mais restrito a este movimento: Chile, Honduras, El Salvador e Panamá, não reconhecem oficialmente a diversidade cultural existente em seus territórios, mas começam a desenvolver políticas educativas específicas voltadas para as populações indígenas.
}

Rev. Diálogo Educ., Curitiba, v. 10, n. 29, p. 151-169, jan./abr. 2010 
A interculturalidade oficial é destinada apenas aos grupos subalternos, mas não tenciona o surgir de uma nova relação social onde diferentes grupos coexistam sem hierarquização de modelos culturais diferenciados. Surgem, então, diferentes grupos que irão propor outra concepção intercultural, como os de-coloniais que apresentaremos a seguir.

\section{Perspectiva crítica e a educação intercultural}

Essa perspectiva focaliza a interculturalidade como um dos componentes centrais dos processos de transformação das sociedades latino-americanas, assumindo um caráter ético e político orientado à construção de democracias em que redistribuição e reconhecimento cultural sejam assumidos como imprescindíveis para a realização da justiça social.

Neste texto, privilegiaremos a apresentação, de modo sintético, da proposta de um grupo formado por pesquisadores que vêm desenvolvendo, a partir da presente década, em diálogo com militantes de movimentos sociais, um programa de investigação sobre "modernidade/colonialidade". Entramos em contato com a produção deste grupo em 2005, por intermédio da professora Catherine Walsh, coordenadora do programa de doutorado em Estudos Culturais LatinoAmericanos, da Universidade Andina Simon Bolívar de Quito (Equador), e para ela,

o conceito de interculturalidade é central à (re)construção de um pensamento crítico-outro - um pensamento crítico de/ desde outro modo-, precisamente por três razões principais: primeiro porque é vivido e pensado desde a experiência da colonialidade [...]; segundo, porque reflete um pensamento não baseado nos legados eurocêntricos ou da modernidade e, em terceiro, porque tem sua origem no sul, dando assim uma volta à geopolítica dominante do conhecimento que tem tido seu centro no norte global (WALSH, 2005, p. 25).

A produção deste grupo tem como uma de suas referências as contribuições do ponto de vista político, social e cultural do peruano Aníbal Quijano e do argentino Walter Mignolo. Aprofundar na compreensão de categorias como geopolítica do poder e do saber, do ser, e da natureza, pensamento crítico fronteiriço, de-colonialidade,

Rev. Diálogo Educ., Curitiba, v. 10, n. 29, p. 151-169, jan./abr. 2010 
entre outras, é fundamental para penetrarmos na tessitura desta abordagem. Não pretendemos realizar neste momento esta empreitada, certamente complexa e que ultrapassa o objetivo do presente texto. No entanto, são necessárias algumas incursões na problemática que estas categorias pretendem abordar, para que possamos ter um entendimento básico da interculturalidade crítica e de-colonial proposta por este grupo e suas implicações educacionais.

Em primeiro lugar, é importante distinguir descolonização e decolonialidade. Os países latino-americanos conquistaram desde o século XIX sua independência política, no entanto, segundo o grupo modernidade/colonialidade, a lógica colonial penetrou profundamente as estruturas, instituições, mentalidades e subjetividades de tal maneira que continua presente e configura as sociedades latino-americanas.

A colonialidade do poder refere-se aos padrões de poder baseados em uma hierarquia (racial, sexual) e na formação e distribuição de identidades (brancos, mestiços, índios, negros). Quanto à colonialidade do saber, refere-se ao caráter eurocêntrico e ocidental como única possibilidade de se construir um conhecimento considerado científico e universal, negando-se outras lógicas de compreensão do mundo e produção de conhecimento, consideradas ingênuas ou pouco consistentes. A colonialidade do ser supõe a inferiorização e subalternização de determinados grupos sociais, particularmente os indígenas e negros. Walsh (2006) menciona também a colonialidade da natureza, entendida como a afirmação da divisão binária entre natureza e sociedade e a negação de perspectivas em que estas realidades estão entrelaçadas e se articulam também com a dimensão da espiritualidade.

Esses autores acreditam que a perspectiva intercultural é um caminho para desvelar os processos de de-colonialidade e construir espaços, conhecimentos, práticas que permitam a construção de sociedades distintas. Para Walsh (2006, p. 21),

mais do que um simples conceito de inter-relação, a interculturalidade assinala e significa processos de construção de conhecimentos 'outros', de uma prática política 'outra', de um poder social 'outro', e de uma sociedade 'outra', formas diferentes de pensar e atuar em relação e contra a modernidade/colonialidade, um paradigma que é pensado através da prática política.

Rev. Diálogo Educ., Curitiba, v. 10, n. 29, p. 151-169, jan./abr. 2010 
A interculturalidade é então concebida como uma estratégia ética, política e epistêmica. Nesta perspectiva, os processos educativos são fundamentais. Por meio deles questiona-se a colonialidade presente na sociedade e na educação, desvela-se o racismo e a racialização das relações, promove-se o reconhecimento de diversos saberes e o diálogo entre diferentes conhecimentos, combate-se as diferentes formas de desumanização, estimula-se a construção de identidades culturais e o empoderamento de pessoas e grupos excluídos, favorecendo processos coletivos na perspectiva de projetos de vida pessoal e de sociedades "outras". A referência às contribuições de Paulo Freire e de Frantz Fanon $^{4}$ é constitutiva da construção de propostas educativas que assumam a perspectiva da educação intercultural crítica e de-colonial.

Lopez (2007, p. 21-22) sintetiza da seguinte maneira o processo de incorporação da perspectiva intercultural no continente:

\begin{abstract}
nestes trinta anos, desde que o termo foi acunhado na região, a aceitação da noção transcendeu o âmbito dos programas e projetos referidos aos indígenas e hoje um número importante de países, do México à Terra do Fogo, veem nela uma possibilidade de transformar tanto a sociedade em seu conjunto como também os sistemas educativos nacionais, no sentido de uma articulação mais democrática das diferentes sociedades e povos que integram um determinado país. Desde este ponto de vista, a interculturalidade supõe agora também abertura diante das diferenças étnicas, culturais e lingüísticas, aceitação positiva da diversidade, respeito mútuo, busca de consenso e, ao mesmo tempo, reconhecimento e aceitação do dissenso, e na atualidade, construção de novos modos de relação social e maior democracia.
\end{abstract}

\footnotetext{
4 Frantz Fanon (1925-1961) foi um psiquiatra, escritor e ensaísta, natural da Martinica, de ascendência africana. Ele ofereceu uma contribuição significativa para a reflexão sobre descolonização e a psicopatologia da colonização. Suas obras foram inspiradas nos movimentos de libertação anticoloniais. Suas obras mais conhecidas são Pele Negra, Máscaras Brancas, (1983) e Os Condenados da Terra, (2005).
}

Rev. Diálogo Educ., Curitiba, v. 10, n. 29, p. 151-169, jan./abr. 2010 
CONSIDERAÇÕES FINAIS

Procuramos neste texto defender a tese de que a educação intercultural na América Latina tem uma trajetória própria e bastante original. Emerge das preocupações com a educação escolar dos grupos indígenas, constituindo esta sua matriz de origem. Também contribuem para o aprofundamento e enriquecimento da perspectiva intercultural, na nossa leitura, as lutas e propostas dos movimentos negros organizados presentes em diferentes países do continente, assim como as múltiplas experiências de educação popular.

Em diferentes países, a interculturalidade foi assumida por políticas públicas distintas, particularmente no âmbito educacional, mas, em geral, essa incorporação se deu na lógica da integração ao modelo social e econômico hegemônico. A perspectiva crítica, em suas diferentes configurações, tem assumido a educação intercultural como um componente importante dos processos de transformação social e construção de democracias em que redistribuição e reconhecimento se articulem. Destacamos nesta perspectiva e proposta de uma educação intercultural crítica e de-colonial por considerá-la de especial significado para os debates em curso no continente.

Por meio das contribuições explicitadas, fica evidenciada a polissemia da expressão educação intercultural, assim como sua complexidade e a originalidade do processo vivido na América Latina, tanto no que diz respeito à gênese do conceito como às suas diferentes leituras, problemática e incidência política e cultural na atualidade.

A perspectiva intercultural no âmbito educativo não pode ser reduzida a uma mera incorporação de alguns temas no currículo e no calendário escolar. Trata-se, de modo especial, da perspectiva crítica, que consideramos ser a que melhor responde à problemática atual do continente latino-americano, de uma abordagem que abarca diferentes âmbitos ético, epistemológico e político -, orientada à construção de democracias em que justiça social e cultural sejam trabalhadas de modo articulado.

O que está em questão atualmente, quando aprofundamos o debate sobre a interculturalidade na América Latina e a própria possibilidade de construção de estados pluriétnicos, plurilinguísticos e, inclusive, plurinacionais, assim como o reconhecimento, construção e diálogo entre diferentes saberes e a afirmação de uma ética na qual diferença cultural, a justiça, a solidariedade e a capacidade de construir juntos se articulem.

Rev. Diálogo Educ., Curitiba, v. 10, n. 29, p. 151-169, jan./abr. 2010 
Trata-se de uma problemática complexa e controvertida. Certamente a educação ocupa um lugar fundamental nesta construção.

\section{REFERÊNCIAS}

COLLET, C. Quero progresso sendo índio: o princípio da interculturalidade na educação escolar indígena. 2001. 150 f. Dissertação (Mestrado em Antropologia Social) - Museu Nacional, Rio de Janeiro, 2001.

FANON, F. Peles negras, máscaras brancas. Rio de Janeiro: Fator, 1983.

Os condenados da terra. Juiz de Fora: Ed. da UFJF, 2005.

FAUNDEZ, A.; FREIRE, P. Por uma pedagogia da pergunta. Rio de Janeiro: Paz e Terra, 1985.

FERREIRA, K. M. A educação escolar indígena: um diagnóstico crítico da situação no Brasil. In: LOPES DA SILVA, A.; FERREIRA, M. (Org.). Antropologia, história e educação: a questão indígena e a escola. São Paulo: Global, 2001.

GOHN, M. G. Educação popular na América Latina no novo milênio: impactos do novo paradigma. ETD- Educação Temática Digital, Campinas, v. 4, n. 1, p. 53-77, 2002.

LÓPEZ, L. E.; KÜPER, Wo. La educación intercultural bilingüe en América Latina: balance y perspectivas. Revista Iberoamericana de Educación - OEI, n. 20, 1999. Disponível em: <http://www.rieoei.org/rie20a02.htm>. Acesso em: 12 jul. 2008.

LÓPEZ, L. E.; SICHRA, I. La educación en áreas índigenas de América Latina: balances y perspectivas. In: HERNAIZ, I. (Org.). Educación en la diversidad. Experiencias y desafíos en la Educación Intercultural. Buenos Aires: IIPE, 2004. p. 121-149.

LÓPEZ, L. E. Trece claves para entender la interculturalidad en la educación latinoamericana. In: PRATS, E. (Org.). Multiculturalismo y educación para la equidad. Barcelona: Octaedro-OEI, 2007. p. 13-44.

MATO, D. (Org.). Políticas de identidades y diferencias sociales en tiempos de globalización. Caracas: FACES, 2003.

Rev. Diálogo Educ., Curitiba, v. 10, n. 29, p. 151-169, jan./abr. 2010 
MEJÍA, V. Y. El modelo de Ayllu: sistematización de Warisata Escuela-Ayllu. In: REUNiÃo ANUAL DE ETNOLOGIA, 19., 2006, La Paz. Anais... La Paz: Museu Nacional de etnografia e folclore, 2006. Disponível em: <http:// www.katari.org/warisata/escuela.pdf.>. Acessado em: agosto 2006.

PÉREZ, E. Warisata La escuela Ayllu. Bolívia: E. Burillo, 1962.

RUSSO, K. Quando 'outros mundos' se encontram: movimentos indígenas e a construção de uma identidade étnica transnacional no Fórum Social Mundial. In: MATO, D.; FERMÍN, A. Cultura y transformaciones sociales en tiempos de globalización: perspectivas latinoamericanas. Buenos Aires: CLACSO Libros, 2007. p. 199-212.

TUBINO, F. La interculturalidad crítica como proyecto ético-político. In: ENCUENTRO CONTINENTAL DE EDUCADORES AGUSTINOS, 1., 2005, Lima. Anais... Lima: Universidad Andina, 2005.

WALSH, C.; GARCÍA, J. El pensar del emergente movimiento afroecuatoriano. Reflexiones (des)de un proceso. In: MATO, D. (Org.). Estudios y otras prácticas intelectuales latinoamericanas en cultura y poder. Caracas: Consejo Latinoamericano de Ciencias Sociales y Universidad central de Venezuela, 2002. p. 317-326.

Pensamiento crítico y matriz (de)colonial- reflexiones latinoamericanas. Quito: Abya-Yala, 2005.

Interculturalidad y colonialidad del poder: un pensamiento y posicionamiento otro desde la 'diferencia colonial. In: WALSH, C. et al. Interculturalidad, descolonización del estado e del conocimiento. Buenos Aires: Signo, 2006. p. 21-70.

Recebido: 27/04/2009

Received: 04/27/2009

Aprovado: 10/09/2009

Approved: 09/10/2009

Rev. Diálogo Educ., Curitiba, v. 10, n. 29, p. 151-169, jan./abr. 2010 